\title{
Reformas, instituições e políticas de saúde no Brasil (1930-1945)
}

\section{Reforms, institutions and health policies in Brazil (1930-1945)}

\author{
Gilberto Hochman*
}

\begin{abstract}
RESUMO
O objetivo geral desse artigo é descrever e analisar de modo sucinto as principais mudanças institucionais e tendências políticas no setor de saúde durante o Primeiro Governo Vargas, em particular na gestão de Gustavo Capanema, no Ministério da Educação e Saúde (1934-1945). Um aspecto enfatizado no artigo é a relação entre as reformas da saúde e as mudanças e ideologia do regime político instaurado em 1930, indicando permanências e rupturas em relação ao período republicano anterior, assim como os impactos dessas reformas sobre a saúde pública no Brasil contemporâneo.

Palavras-chave: saúde pública, reforma do Estado, Ministério da Educação e Saúde.
\end{abstract}

\begin{abstract}
The general aim of this article is to describe and analyse in a concise way the main institutional changes and political tendencies in the health policy field during the First Vargas Government, particularly during Gustavo Capanema's administration at the Ministry of Education and Health (19341945). One aspect emphasised in the article is the relation between the reforms on health and the changes in the ideology of the political regime established in 1930, indicating permanence and discontinuity regarding the previous republican period as well as the impacts of those reforms on public health in contemporary Brazil.

Key-words: public health, State reform, Ministry of Education and Health.

* Doutor em Ciência Política (IUPERJ). Pesquisador da Casa de Oswaldo Cruz / Fiocruz. E-mail: hochman@fiocruz.br
\end{abstract}




\section{Introdução}

Esse trabalho se propõe a apresentar as transformações nas políticas públicas de saúde em um período que é um marco na história do Brasil e uma marca na historiografia brasileira: O primeiro governo de Getúlio Vargas (19301945). O movimento político-militar que, com apoios populares, levou Vargas ao poder, a Revolução de 30, congregou descontentes e descontentamentos de diversos tipos com um país governado por representantes das oligarquias estaduais, em particular pelos interesses agro-exportadores dos estados do sudeste-sul do país. As críticas e insatisfações eram também as mais variadas e ganharam contornos mais graves com a crise de 1929. Em especial, a baixa incorporação política dos setores médios urbanos; as dificuldades de acesso ao poder de oligarquias não-centrais; a corrupção política e eleitoral; a fragilidade do poder público federal; a ausência de integração nacional; a repressão policial aos movimentos reivindicatórios de trabalhadores; o clientelismo e o patrimonialismo; o atraso econômico; a carência de políticas sociais e as precárias condições de vida da população. ${ }^{1}$

O regime que se instaurou em 1930, e em especial na sua fase autoritária pós-1937, prometeu um novo começo, uma república nova em país renovado e, em especial, um novo homem brasileiro. Em particular, historiadores indicam que o Estado Varguista produziu ativamente a identidade dos "trabalhadores do Brasil", associando trabalho e direitos de cidadania e enfrentando como prioridade a "questão social", construiu o mito de Vargas como "pai dos pobres" e uma política que supunha um Estado forte que intervém e organiza os interesses sociais em conflito, produz compromissos, constituindo-se como ente mais autônomo em relação à sociedade. Seriam ações e ideologias imersas em um contexto internacional de crítica ao capitalismo em suas formas liberal-democráticas com fortes tendências autoritárias de direita e de esquerda, e de amplas e persistentes conseqüências políticas e ideológicas na política brasileira.

Parte considerável da historiografia brasileira que se debruçou sobre o século XX se dedicou a argüir a natureza, os impactos e o legado de um período cujo principal personagem e seus ideólogos buscaram cancelar o passado 
e adjetivar a primeira experiência republicana (1889-1930) como "velha". ${ }^{2}$ Modernização, desenvolvimento, nacionalismo, antiliberalismo, centralização política e administrativa, controle político e extensão da proteção social foram os novos e centrais componentes dos discursos, das intenções e das principais ações públicas do novo regime político que se instaurou ao longo da década de 1930 e findou em 1945.

O objetivo central desse trabalho é abordar um tema pouco estudado tanto pela bibliografia dedicada à saúde pública como por aquela que se debruçou sobre o período 1930-1945, que priorizou os temas do trabalho, da educação e cultura: a extensão das mudanças operadas pelo regime varguista no campo da saúde pública. Um campo desafiado por um quadro sanitário que, mesmo com avanços do poder público e do conhecimento biomédico, continuava sendo dramático em 1930: a febre amarela ainda ameaçava a capital e os portos litorâneos, a malária grassava pelo interior do país, a hanseníase ganhava a atenção dos médicos e a tuberculose continuava sendo o mais grave problema sanitário das cidades. A criação do Ministério da Educação e Saúde Pública (MESP) ainda em novembro de 1930 parecia ser também a realização parcial dos anseios do vigoroso movimento sanitarista da Primeira República (CASTRO SANTOS, 1985; HOCHMAN, 1998). Sugiro que, apesar de identificarmos elementos de continuidade, ${ }^{3}$ as modificações operadas no regime varguista marcaram de forma profunda e longeva o campo da saúde pública no Brasil.

\section{Reformas da saúde pública: 1930-1945}

As reformas da saúde pública acompanharam as oscilações políticas do Governo Provisório, período marcado pela instabilidade política e por sucessivas mudanças no comando do Ministério da Educação e Saúde Pública até a posse de Gustavo Capanema em 26 de julho de 1934.

2 Há uma extensa bibliografia sobre o período da qual destaco alguns dos trabalhos mais abrangentes: Bomeny (2001); D‘Araújo (1999); Gomes (1988; 2000); Oliveira, Velloso e Gomes (1982); Pandolfi (1999); Schwartzman (1983; 1984).

3 O argumento sobre fortes continuidades foi desenvolvido por Hochman e Fonseca (1999). 
Todo o setor público havia passado, a partir de 1930, por uma série de reformas que já vinham sendo anunciadas antes mesmo da mudança de governo - algumas já apareciam na plataforma de campanha eleitoral de Vargas em 1929 - e se enquadraram num amplo programa de planejamento e reforma governamental. Os ideais de formação de um Estado robusto e centralizado pareciam ser realizados pela constituição de um aparato governamental que alcançasse todo o território nacional, integrando as esferas federal, estadual e municipal em um projeto político-administrativo mais unificado. Era uma clara reação ao federalismo extremado da primeira constituição republicana. A criação do MESP estava inserida nessa perspectiva de reforma administrativa. ${ }^{4}$

Inicialmente, a criação do Ministério não trouxe nenhuma alteração para a saúde pública, significando apenas a incorporação do já existente Departamento Nacional de Saúde Pública (DNSP), criado em 1920. Posteriormente, foi sofrendo modificações provisórias por meio de uma legislação fragmentada e que atendia somente às necessidades conjunturais. No final do ano de 1930, já haviam sido delineadas algumas das diretrizes que orientariam a reforma administrativa implementada por Vargas: fortalecer a organização administrativa federal e introduzir medidas de racionalização administrativa. Porém, segundo alguns analistas da reforma administrativa, nesse período acabaram por não passar de meros atos formais (WAHRLICH, 1983).

Em seus quatro primeiros anos, até a indicação de Capanema para o cargo, ocuparam a pasta ministerial três diferentes ministros: Francisco Campos, Belisário Penna e Washington Pires. Diferentemente do Ministério do Trabalho, Indústria e Comércio, que ao longo deste período viu serem definidas as linhas mestras que norteariam seu desenvolvimento, o MESP chegou ao final do chamado Governo Provisório sem objetivos definidos para sua estrutura administrativa e sem claras linhas de ação. Apesar das inúmeras alterações que sofreu, nenhuma delas representou uma mudança importante, tendo em alguns momentos significado a própria paralisação de atividades, misturando-se às incertezas políticas e à crise econômica e penúria orçamentária do início da década de 1930. No que dizia respeito à saúde pública, o MESP, nos seus primeiros anos, significava, em grande medida, o Departamento Nacional de Saúde Pública criado em fins de 1919 e herdado da República Velha (Hochman, 1998).

4 Sobre a reforma administrativa, ver Cunha (1963) e Wahrlich (1983). Para informações sobre as mudanças do MESP no período e sobre a história institucional e constitucional da saúde pública utilizo Gama e Silva e Marques (s.d.) e Rodrigues e Alves (1977). 
O marco mais definitivo no processo de construção institucional da saúde pública enquanto política estatal foi a gestão do Gustavo Capanema no Ministério da Educação e Saúde Pública (1934-45), a mais longa permanência de um ministro nas pastas de educação e saúde. Foi a reforma do o Ministério que, proposta em 1935 e implementada por Capanema a partir de janeiro de 1937, definiu rumos para a política de saúde pública, reformulando e consolidando a estrutura administrativa e adequando-a aos princípios básicos que haviam definido a política social do Estado Novo. Foi a partir dessa reforma que o Ministério passou a se denominar Ministério da Educação e Saúde (MES). A segunda grande reforma ocorreu em 1941 com a criação dos Serviços Nacionais, que verticalizaram as campanhas de combate a doenças específicas e às grandes endemias.

Portanto, serão essas duas reformas empreendidas por Capanema - uma mais geral da estrutura do MESP e outra mais específica nas ações de saúde que definirão e consolidarão a estrutura administrativa e institucional da saúde pública, que permaneceu quase inalterada até a criação do Ministério da Saúde em 1953, e de certo modo até o final dos anos 80.

Em termos de criação institucional, os marcos foram as Delegacias Federais de Saúde, os Serviços Nacionais e a instituição das Conferências Nacionais de Saúde. A criação do Serviço Especial de Saúde Pública (SESP) em 1942, por meio de um acordo com o governo norte-americano, é outro marco importante (CAMPOS, 2000). Do ponto de vista das ações principais da saúde pública, o foco recaiu sobre o combate à malária e à tuberculose, nesse caso uma novidade em relação ao período pré-1930, além da formulação de um plano nacional de combate à lepra. A febre amarela, tradicional alvo da saúde pública, e que retornara à Capital federal em 1928, depois de duas décadas de ausência, continuou a merecer a atenção do governo federal e a parceria da Fundação Rockefeller, em especial nos anos 40, para a fabricação da vacina (BENCHIMOL, 2001).

Com essas reformas a saúde pública passava a espelhar as orientações mais gerais da política varguista de centralização política e administrativa e verticalização das ações estatais. O principal responsável pela implementação das reformas na área da saúde, o médico João de Barros Barreto, foi empossado como diretor do Departamento Nacional de Saúde (DNS) em fevereiro de 1937, um mês após a reforma do ministério ter sido aprovada, permanecendo até 1939 e retornando ao cargo em 1941, deixando o cargo em 1945, com a queda de Vargas. Interiorizar a saúde pública - agenda clássica do sanitarismo - parecia ser possível com o incremento da presença do MES nos Estados e o formato institucional escolhido foi verticalizar essas ações que seriam especializadas por enfermidade a ser enfrentada, coordenadas por um núcleo central que residiria no Ministério e implementadas de modo hierárquico nos 
estados e nos municípios. Com intervenções políticas nos Estados, autoritarismo e com crescentes limites constitucionais às autonomias estaduais, seriam removidos os obstáculos para a realização do ideal centralizador do movimento sanitarista da década de 1920.

Inicialmente, com a aprovação da Reforma em 1937 (Lei n. 378, 13/01/ 1937), o território brasileiro foi dividido em oito regiões, contando cada uma delas com uma Delegacia Federal de Saúde. As Delegacias tinham como função supervisionar as atividades necessárias à colaboração da União com os serviços locais de saúde pública e assistência médico-social e com instituições privadas, além da inspeção dos serviços federais de saúde. Estavam assim distribuídas: (1) Distrito Federal e Estado do Rio de Janeiro; (2) Território do Acre e Estados do Amazonas e Pará; (3) Estados do Maranhão, Piauí e Ceará; (4) Estados do Rio Grande do Norte, Paraíba, Pernambuco e Alagoas; (5) Estados de Sergipe, Bahia e Espírito Santo; (6) Estados de São Paulo e Mato Grosso; (7) Estados do Paraná, Santa Catarina e Rio Grande do Sul e (8) Estados de Minas Gerais e Goiás. Suas sedes foram estabelecidas nas seguintes cidades: Rio de Janeiro, Belém, Fortaleza, Recife, Salvador, São Paulo, Porto Alegre e Belo Horizonte.

Dessa forma, o Governo Federal pretendia ampliar a sua presença nas diversas regiões do país, implementando e supervisionando as ações de saúde pública. Cada delegacia federal de saúde funcionaria como um braço do Ministério em uma determinada região e estabelecia uma relação íntima com os serviços sanitários estaduais, inclusive com a nomeação dos seus chefes. A instauração da ditadura em 10 de novembro de 1937 facilitou a implementação de uma reforma que pretendia aumentar a presença dos serviços sanitários federais nos estados, reformulando a relação entre estes e a União. Essa preocupação parecia ser uma resposta aos que indicavam que os serviços sanitários, a despeito de seus objetivos nacionais, concentravam-se, na prática, no Distrito Federal. Em um balanço feito em 1942, Barros Barreto indicava que um número expressivo de estados estava organizando ou remodelando seus departamentos de saúde à luz das novas diretrizes federais. Um dado indicativo desse processo de reforma e a articulação dos estados com os serviços federais de saúde, apresentado neste balanço, é que 13, dos então 19 estados, tinham como diretores de seus departamentos de saúde, ou como assistentes de diretor, técnicos vinculados diretamente ao DNS/MES (BARROS BARRETO, 1942, p. 205-206). ${ }^{5}$

${ }^{5}$ Cabe ilustrar que também é a gestão Capanema que consolida a condução da educação pública como responsabilidade da União, que, antes de Vargas, esteve sob responsabilidade dos estados e cria o Sistema Nacional de Educação. 
Além das Delegacias Federais de Saúde, a reforma de 1937 instituiu as Conferências Nacionais de Saúde (CNS), que deveriam reunir periodicamente delegações de todos os estados em um fórum nacional e de caráter oficial para discutir os temas de saúde pública. De acordo com o ambiente político reinante no país e a perspectiva técnica que informava as reformas, Gustavo Capanema definia as CNS como

\begin{abstract}
... conferências de administradores que terão apenas o objetivo de estudar e assentar providências de ordem administrativa. Por meio delas, poderá ainda a União coordenar a execução dos planos nacionais que forem estabelecidos. (Arquivo Gustavo Capanema, FGV/CPDOC, GC.34.06.21.).
\end{abstract}

A criação das Conferências complementava as propostas institucionais anteriores e seguia os princípios gerais que as orientaram, calçados na preocupação em estabelecer parâmetros mais precisos nas relações e atribuições da União com os estados e municípios. Utilizando-se recursos financeiros e prestação de assistência técnica, os problemas dos estados deveriam ser tratados conjunta e sistematicamente, sem privilégios. Este objetivo é claramente indicado na lei que aprovou o novo formato do Ministério, contendo um capítulo específico relativo às formas de ação da União. Nele, o governo indica que as CNS, assim como as Conferências Nacionais de Educação criadas pela mesma legislação, estavam destinadas a facilitar ao Governo Federal o conhecimento das atividades concernentes à educação e à saúde, orientando a execução dos serviços estaduais e locais e a concessão de auxílios e subvenções federais.

Do ponto de vista da reforma, as CNS constituíam um espaço privilegiado para a articulação entre o governo federal e os estados, viabilizando a sistematização de normas técnicas e administrativas da área da saúde. Permitiriam que se ajustassem os mecanismos burocráticos e administrativos que dariam suporte à definição das prioridades, a uma supervisão que aspirava ser criteriosa e a uma pretensão de controlar o setor. Dessa forma, o perfil delineado para o funcionamento das Conferências era o de um espaço para administradores e técnicos de saúde. Como diziam respeito a atividades exclusivamente de caráter público, as CNS aglutinariam representantes dos órgãos públicos de saúde na esfera federal e estadual, para discussão e deliberação das questões administrativas relativas à saúde pública. 
A Primeira Conferência Nacional de Saúde foi realizada entre 10 e 16 de novembro de 1941, no Rio de Janeiro, logo após a realização da Conferência Nacional de Educação. ${ }^{6}$ Algumas proposições aprovadas nessa Conferência revelam a combinação da histórica agenda dos sanitaristas e das características da política varguista. De um lado, reafirmam a necessidade de centralização da capacidade de normatização legal e administrativa das ações de saúde pública nas mãos do MES, ainda que os estados e municípios fossem os executores dessas ações. De outro, a manutenção da possibilidade de acordos entre estados e governo federal para que este desenvolvesse diretamente ações de saúde, preferencialmente de combate às endemias rurais (Arquivos de Higiene, abril, 1941, p. 64-65; Arquivo Gustavo Capanema, CPDOC/FGV, GC 36.05.26). De certo modo, as CNS deveriam substituir os congressos da Sociedade Brasileira de Higiene que, com cinco edições até serem interrompidos em 1930, eram os espaços de reunião científica e política dos profissionais do campo da saúde pública. Esses congressos só puderam ser retomados em 1947 e mantiveram a sua importância técnica e política até os anos $50 .^{7}$

Entre as propostas apresentadas pela I Conferência Nacional de Saúde, e implementadas na década de 1940, estava a atualização do modelo de interação entre estados e União iniciado na República Velha: convênios entre serviços estaduais e federais para implementação de ações sanitárias. Diferente da experiência iniciada no final da década de 1910, esses acordos estavam agora emoldurados pela centralização e verticalização do Estado Novo, com incremento do poder do DNS no controle e de normatização das atividades de saúde pública em todo o país (HOCHMAN; FONSECA, 2000).

No início de 1941, Capanema propôs uma nova alteração na estrutura do MES, procurando intensificar a presença dos órgãos federais de saúde nos estados de forma mais centralizada, criando para isso os Serviços Nacionais de Saúde, a mais duradoura invenção institucional da gestão Capanema/Barros Barreto. Reafirmava o projeto político de consolidar uma estrutura administrativa com uma forte coordenação e supervisão federal. Na apresentação dessa proposta de reorganização do Departamento Nacional de Saúde (DNS) ao presidente da República, destaca os dois princípios que a inspiraram, o de maior coordenação e de atuação ampliada:

${ }^{6}$ Para a I Conferência Nacional de Educação ver Horta (2000).

${ }^{7}$ Ao contrário, as CNS tiveram apenas duas edições até 1964 (1950 e 1963) e só ganharam visibilidade com a redemocratização do país a partir de 1985, com a chamada "Constituinte da Saúde", a VIII Conferência Nacional de Saúde realizada em 1986. 
A reforma proposta em 1935 buscou, a este respeito, nacionalizar o Ministério, mercê da firme decisão assentada por V.Excia no sentido de ampliar a atuação federal, quanto aos problemas de saúde, de modo que ela deixasse de considerar preferentemente o Distrito Federal para abranger, de maneira sistemática, todo o território nacional. (...) O projeto ora proposto procura assentar as bases de solidificação dos trabalhos desenvolvidos, dando ao Departamento Nacional de Saúde um sistema de órgãos adequados não só a manter mas ainda a desenvolver os empreendimentos de caráter nacional iniciados. Representa como se vê, o projeto de decreto-lei menos um traçado de perspectivas novas, menos uma promessa de novas realizações do que uma consolidação da experiência já realizada e uma sistematização dos esforços já empreendidos. ${ }^{8}$

Essa reforma reafimava que a saúde pública deveria atuar privilegiando as doenças infecto-contagiosas, que atingiam a totalidade da comunidade nacional e não grupos específicos. Os Serviços Nacionais, tendo cada um deles um diretor, seriam supervisionados pelo DNS, que acompanhava o trabalho desenvolvido nas diferentes regiões do país. Eram os seguintes os serviços nacionais: da Peste; de Tuberculose; de Febre Amarela; do Câncer, de Lepra, de Malária, de Doenças Mentais, de Educação Sanitária, de Fiscalização da Medicina, de Saúde dos Portos, Serviço Federal de Bio-Estatística e Serviço Federal de Águas e Esgotos. O Serviço de Febre Amarela e o Serviço de Malária do Nordeste, vinculados às ações da Fundação Rockefeller, antecederam a criação dos respectivos serviços nacionais. A principal orientação e missão dos serviços nacionais criados em 1941 era debelar surtos epidêmicos e estabelecer métodos de controle e prevenção, em um trabalho conjunto com as Delegacias Federais de Saúde e com os governos estaduais. Dessa forma, o governo federal, por meio da equipe técnica que atuava nos estados (médicos sanitaristas, guardas sanitários, enfermeiras, engenheiros), buscava aumentar sua presença nos recantos mais remotos do país, conjugando centralização política com alguma forma de descentralização administrativa.

Reforçado pelo forte apelo ideológico que apontava para um projeto de construção nacional associado à centralização política, a reorganização desses serviços acentuava a intenção do Ministério em estender os limites de sua

${ }^{8}$ Apresentação da proposta de reorganização do DNS ao presidente Vargas em 24/03/ 1941. Arquivo Gustavo Capanema, CPDOC/FGV (GC 35.02.19). 
atuação, procurando projetar-se em todo o território do país, planejando, coordenando e executando, associado aos estados, ações de saúde e saneamento. As atividades de saúde pública deveriam se voltar principalmente para a prevenção e o combate de doenças como a tuberculose, a malária, a febre amarela e a peste, tendo como foco a "coletividade", deixando para a assistência médica previdenciária e para a assistência pública as ações mais individualizadas. Duas passagens de Capanema expressam essa perspectiva,

... sem descuidar dos serviços da capital da República, antes até, melhorando-os a ponto de torná-los modelares, a ação do ministério será cada vez mais nacional, fundamentalmente nacional, atendendo assim a um dos objetivos primordiais da reforma (Discurso de Capanema ao dar posse ao Dr. João de Barros Barreto na direção do DNS, Jornal do Comércio, 04 fev. 1937).

À saúde pública não interessa o caso individual, seja um caso de doença, seja qualquer outra situação especial relativa à saúde ou ao corpo. $\mathrm{O}$ caso individual só interessa à saúde pública se puder afetar a coletividade, se for capaz de pôr a coletividade em perigo. Fora disso, dele não se ocupará a saúde pública (Arquivo Gustavo Capanema, FGV/CPDOC, GC.34.06.2..F Pasta VI).

As preocupações com a saúde do homem rural estavam diretamente vinculadas a doenças infecto-contagiosas, que implicavam riscos à coletividade, e marcaram a atuação do MES. Toda a estrutura administrativa se construiu tendo como prioridade o combate às doenças transmissíveis eleitas como prioritárias, como pode ser observado na organização dos serviços nacionais. O campo de atuação da saúde pública foi sendo delimitado a partir da conjugação da verticalização das ações políticas e o foco em doenças endêmicas e infecto-contagiosas voltadas para a "saúde das populações".

Cabe indicar que a atenção materno-infantil tinha uma posição particular nas propostas para a política de saúde, quando foram criados serviços específicos para a infância, separados dos serviços de saúde destinados à população em geral. Com a reforma de 1937, foi criada a Divisão de Amparo à Maternidade e a Infância. Pouco depois, em fevereiro de 1940, ela seria extinta com a criação do Departamento Nacional da Criança, desvinculado do DNS. Ambos estiveram sob a direção de Olinto de Oliveira, que em suas atividades e textos acentuava a necessidade de que os problemas relaciona- 
dos à infância não deveriam estar subordinados à área da saúde pública, mas em um órgão autônomo dentro do MES (souZA, 2000).

A política de extensão da proteção médico-assistencial aos trabalhadores associados aos Institutos de Aposentadoria e Pensões, ${ }^{9}$ dissociada das ações de saúde pública, não foi apenas resultado de uma estratégia governamental específica. Contou com a recusa dos profissionais e dirigentes vinculados à saúde pública em abrir mão de uma agenda rural e com a sua rejeição programática de incorporar ações médico-curativas no campo institucional da saúde pública (FONSECA, 2000; HOCHMAN, 2001).

\section{Considerações finais}

Se o Estado Novo atualizou a "herança sanitarista" da Primeira República, também a renovou e inovou. Em primeiro lugar, o Serviço Nacional de Tuberculose proporcionou a primeira aproximação entre os Institutos de Aposentadoria e Pensões com o campo da saúde pública, das práticas assistenciais e curativas individualizadas com a medicina preventiva de corte coletivo. Seria o reconhecimento da inviabilidade de tratar uma doença fortemente presente entre os trabalhadores urbanos a partir de orientações, instituições e profissionais diferentes. Esse encontro entre ações preventivas-educativas e práticas curativas foi lento e demorado. Do ponto de vista institucional, a unificação da saúde pública com a assistência médica previdenciária só ocorreria no início da década de 1990.

Em segundo lugar, a perspectiva de agências de alcance nacional, que a partir do governo central normatizavam e coordenavam ações sobre endemias e doenças específicas, promoveu uma especialização inédita no interior do Departamento Nacional de Saúde (DNS). Esse reordenamento da estrutura administrativa da saúde pública, com sua incorporação em novos formatos e conteúdos à agenda oficial do governo, demandou uma nova especialização: o profissional de saúde empregado pelo Estado. Acelerou-se um processo iniciado ainda na República Velha: a diferenciação entre os médicos clínicos

9 Em 1940, existiam Institutos de Aposentadoria e Pensões para marítimos, comerciários, bancários, industriários, empregados em transportes e cargas, e serviços públicos. Ver Malloy (1986) e Hochman (1992). 
e os higienistas/sanitaristas por meio de cursos de higiene e saúde pública ministrados pelo Instituto Oswaldo Cruz e pelas Faculdades de Medicina, da ida de médicos brasileiros para universidades norte-americanas e do treinamento nos próprios serviços. O DNS implantou, a partir de 1938, uma política de capacitação de quadros técnicos para os serviços nacionais e estaduais (BARROS BARRETO, 1942). A diferenciação não foi apenas intra-elite médica, mas também, ainda que de forma mais lenta, entre elites políticas e elites médicas. Foi esse processo de formação de um grupo de médicos, empregado do Estado e especializado em saúde pública, que deu início a essa separação entre elites estatais profissionais e elites políticas. Assim foi se conformando uma comunidade profissional produzida e associada ao poder público, que passa a ser interlocutor dos grupos que tinham interesses vinculados às atividades públicas nas áreas da saúde e do saneamento.

A estruturação e consolidação da carreira de sanitarista ocorreram, portanto, não por acaso, junto com as reformas que procuraram definir e expandir a atuação do Estado na área da saúde pública por todo o país. À medida que foram sendo definidas as prioridades para a saúde pública, foram também se reafirmando os requisitos necessários para a conformação de uma especialidade médica regulamentar. Ao mesmo tempo era esta mesma geração que intervinha, contribuindo para a construção deste aparato institucional, definindo prioridades e acumulando experiências no trabalho cotidiano pelo interior do país, atuando tanto como formuladores de propostas políticas para o setor como implementadores de políticas. Fica, portanto, muito difícil separar o processo de institucionalização da saúde pública, que se desenvolve a partir dos anos 30, da trajetória pessoal e profissional dessa geração que se constituiu ao longo deste processo (FONSECA, 2000). Parte dessa geração de médicos-sanitaristas ocuparia os principais postos do Ministério da Educação e Saúde, e depois de 1953, do Ministério da Saúde.

Em terceiro lugar, esse período assiste ao incremento da participação de instituições e técnicos americanos em serviços de saúde no Brasil. Basicamente três serviços retratam esta influência: o Serviço de Malária do Nordeste, o Serviço de Febre Amarela e o Serviço Especial de Saúde Pública. A presença norte-americana contribuiu fortemente na estruturação dos serviços, na formação de profissionais da área (médicos, engenheiros, enfermeiras), na difusão de certos princípios orientadores das atividades de saúde pública (como por exemplo na ênfase dada à educação em saúde e o estabelecimento de Centros de Saúde) e, por terem esses serviços atuado principalmente na área rural, no incremento da presença da saúde pública no interior do país (FARIA; CASTRO SANTOS, 2003; MARINHO, 2001). 
A Fundação Rockefeller, que já estava presente no país desde a década de 1910, atuava durante a década de 30 no Serviço de Febre Amarela, por meio de contratos com o governo brasileiro, sob o comando de Fred Soper e Sérvulo Lima. O combate à doença se realizava por intermédio de postos instalados em núcleos rurais pelo interior do país, em áreas de grande infestação. Paralelamente, desde setembro de 1938, a Fundação Rockefeller vinha concentrando suas atividades em uma grande campanha de erradicação do Anopheles Gambiae, mosquito vetor da malária que invadira o nordeste brasileiro nos anos 30 (GADELHA; PACKARD, 1994; FRANCO, 1969). O sucesso dessa campanha inspirou o debate nacional e internacional sobre a erradicação da malária nos anos 40 e 50, com impactos na organização do Serviço Nacional de Malária. Essa presença foi aprofundada com o Serviço Especial de Saúde Pública (SESP) foi criado durante a Segunda Guerra Mundial, em 1942, por meio de um convênio entre o governo brasileiro e o governo americano, este representado pelo Instituto de Assuntos Interamericanos (IAIA) (CAMPOS, 2000).

Assim, apesar de continuar longe de ter logrado alcance nacional e de produzir soluções para os problemas sanitários do país, a saúde pública, na gestão de Gustavo Capanema, tornou-se institucionalmente mais complexa, estabeleceu raízes e contradições que perduraram décadas, e revela diferentes e intricadas faces do Estado varguista e da saúde pública brasileira. Em particular, organizou, centralizou e profissionalizou a saúde pública, mantendo-a fortemente associada ao ideário de construção da nacionalidade por meio de um Estado forte e autoritário.

\section{REFERÊNCIAS}

BARROS BARRETO, J. de. A organização da saúde pública. Arquivos de Higiene, MES/DNS, v. 12, n. 2, p. 169-215, 1942.

BENCHIMOL, J. (Coord.). Febre amarela: a doença e a vacina, uma história inacabada. Rio de Janeiro: Fiocruz, 2001.

BOMENY, H. Constelação Capanema: intelectuais e políticas. Rio de Janeiro: FGV/ USF, 2001.

CAMPOS, A. L. V. Políticas internacionais de saúde na era Vargas: o Serviço Especial de Saúde Pública. In: GOMES, A. C. (Org.). Capanema: o ministro e seu ministério. Rio de Janeiro: FGV/USF, 2000. p. 195-220. 
CASTRO SANTOS, L. A. O pensamento sanitarista na Primeira República: uma ideologia de construção da nacionalidade. Dados, v. 28, n. 2, p. 193-210, 1985.

CUNHA, M. W. V. da. O sistema administrativo brasileiro. Rio de Janeiro: CBPE, 1963.

D‘ARAÚJO, M. C. (Org.). As instituições brasileiras da Era Vargas. Rio de Janeiro: Eduerj/FGV, 1999.

FARIA, L. R. de; CASTRO SANTOS, L. A. A Reforma Sanitária no Brasil: ecos da Primeira República. Bragança Paulista: Edusf, 2003.

FAUSTO, B. A Revolução de 30. 13. reimp. São Paulo: Brasiliense, 1995.

FONSECA, C. M. O. Trabalhando em saúde pública pelo interior do Brasil: lembranças de uma geração de sanitaristas (1930-1970). Ciência e Saúde Coletiva, v. 5, n. 1, p. 393-411, 2000.

FRANCO, O. História da febre amarela no Brasil. Rio de Janeiro: MS/DNER, 1969.

GADELHA, P. E.; PACKARD, R. A land filled with mosquitos: Fred L. Soper, The Rockefeller Foundation, and The Anopheles Gambiae invasion of Brazil. Parassitologia, v. 36, p. 197-213, 1994.

GAMA e SILVA, J. S.; MARQUES, L. Evolução do Ministério da Educação e Saúde. Rio de Janeiro: Divisão de Pesquisas do Instituto Brasileiro de Administração, Fundação Getúlio Vargas, [s.d.].

GOMES, A. M. de C. A invenção do trabalhismo. Rio de Janeiro: Vértice/Iuperj, 1988.

. Capanema: o ministro e seu ministério. Rio de Janeiro: FGV/USF, 2000.

HOCHMAN, G. Os cardeais da previdência social: gênese e consolidação de uma elite burocrática. Dados, v. 35, n. 3, p. 371-401, 1992.

. A era do saneamento - as bases da política de saúde pública no Brasil. São Paulo: Anpocs/Hucitec, 1998.

. A saúde pública em tempos de Capanema: inovações e continuidades. In: BOMENY, H. (Org.). Constelação Capanema: intelectuais e políticas. Rio de Janeiro/Bragança Paulista: FGV/Edusf, 2001. p. 127-151.

HOCHMAN, G.; FONSECA, C. M. O. A I Conferência Nacional de Saúde: reformas, políticas e saúde pública em debate no Estado Novo. In: GOMES, A. C. (Org.). Capanema: o ministro e seu ministério. Rio de Janeiro: FGV/USF, 2000. p. 173-193.

. O que há de novo? Políticas de saúde pública e previdência, 1937-45. In: PANDOLFI, D. (Org.). Repensando o Estado Novo. Rio de Janeiro: FGV, 1999. p. 173-193. 
HORTA, J. S. B. A I Conferência Nacional de Educação ou de como monologar sobre educação na presença de educadores. In: GOMES, A. C. (Org.). Capanema: o ministro e seu ministério. Rio de Janeiro: FGV/USF, 2000. p. 143-172.

MALLOY, J. A política de previdência social no Brasil. Rio de Janeiro: Graal, 1986.

MARINHO, M. G. M. S. Norte Americanos no Brasil: um estudo sobre a Fundação Rockefeller na Universidade de São Paulo. Campinas: Editores Associados/USF, 2001.

OLIVEIRA, L. L.; VELLOSO, M. P.; GOMES, A. M. C. Estado Novo: ideologia e poder. Rio de Janeiro: Zahar, 1982.

PANDOLFI, D. (Org.). Repensando o Estado Novo. Rio de Janeiro: FGV, 1999, p. 173-193.

RODRIGUES, B. de A.; ALVES, A. L. Evolução institucional da saúde pública. Brasília: Ministério da Saúde, 1977.

SCHWARTZMAN, S. Estado Novo, um auto-retrato. Rio de Janeiro/Brasília: Campus/ UNB, 1983.

SCHWARTZMAN, S.; BOMENY, H. M. B. C.; RIBEIRO, V. M. Tempos de Capanema. São Paulo: Paz e Terra/Edusp, 1984.

SOUZA, C. P. de. Saúde, educação e trabalho de crianças e jovens: a política social de Getúlio Vargas. In: GOMES, A. C. (Org.). Capanema: o ministro e seu ministério. Rio de Janeiro: FGV/USF, 2000. p. 221-249.

WAHRLICH, B. M. de S. Reforma administrativa na era de Vargas. Rio de Janeiro: FGV, 1983.

Texto recebido em 23 nov. 2004 Texto aprovado em 03 jan. 2005 